Short Paper

\title{
Lipase Activity in Scallop Hepatopancreas
}

\author{
Yutaka Itabashi and Toru Ota \\ Department of Chemistry, Faculty of Fisheries, Hokkaido University, Minato, Hakodate, Hokkaido 041, Japan \\ (Received October 4, 1993)
}

Key words: scallop, Patinopecten yessoensis, lipase, triacylglycerol, mid-gut gland

The high content of free fatty acids in the lipids of scallop hepatopancreas suggests lipase activity in the tissue, ${ }^{1,2)}$ but virtually nothing is known about it. We found that acetone-ether powders from scallop hepatopancreas are capable of hydrolyzing the ester bonds of the $s n-1(3)$ position of long-chain triacylglycerol molecules.

Acetone-ether powders were prepared as described by Bier $^{3)}$ from the hepatopancreas of living scallops Patinopecten yessoensis and used without further purification. For the assay, the method of Luddy et al. $^{4}$ ) was modified. The acetone-ether powder $(50 \mathrm{mg})$ was added to a solution containing olive oil triacylglycerols $(5 \mathrm{mg}), 22 \% \mathrm{CaCl}_{2}$ $(0.2 \mathrm{ml}), 0.05 \%$ sodium chorate $(0.5 \mathrm{~m} l)$, and $0.32 \mathrm{M}$ universal buffer (Britton-Robinson, $\mathrm{pH} 7.02 \mathrm{ml}$ ). The digestion was carried out in a screw-cap vial by stirring at $700 \mathrm{rpm}$ for $20 \mathrm{~h}$ at $20^{\circ} \mathrm{C}$. To avoid acyl migration under the acidic and alkaline conditions of $s n-1,2(2,3)-$ diacylglycerols released during enzymatic hydrolysis, the solution was kept at $\mathrm{pH} 7.0$. The reaction products were extracted with ether without acidification and separated by thin-layer chromatography (TLC) on silica gel G $(0.5 \mathrm{~mm}$ thickness) impregnated with $5 \%$ boric acid. ${ }^{5)}$ Spots were

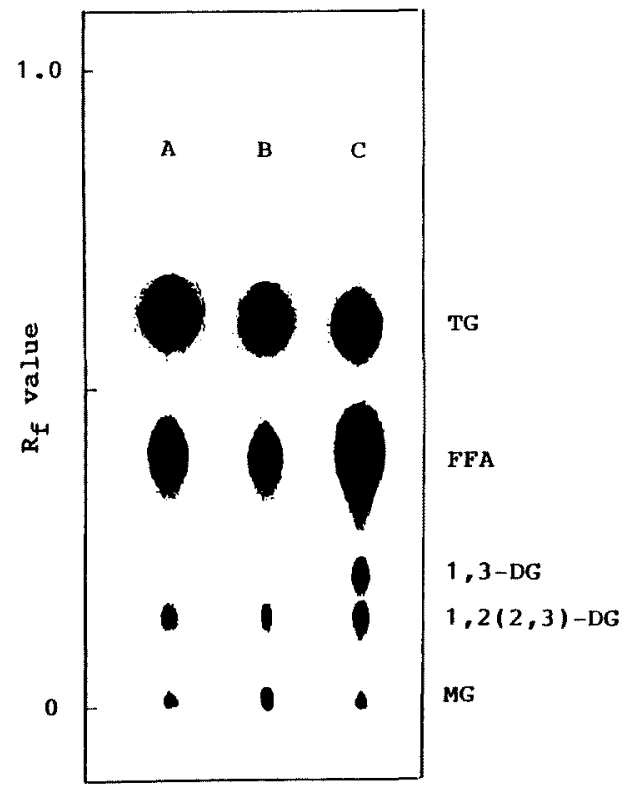

Fig. 1. TLC separation of the hydrolysates of olive oil triacylglycerols by lipases of scallop hepatopancreas (A), porcine pancreas (B), and Candida cylindracea (C).

TG, triacylglycerols; FFA, free fatty acids; DG, diacylglycerols; MG, monoacylglycerols. 15,100 , and 350 units of A, B, and $C$ were used for the reactions, respectively. detected by exposing to iodine vapor and identified by comparing their $R f$ values with those of authentic standards. Porcine pancreatic and Candida cylindracea lipases (Sigma) were also used as standards of 1,3-specific and non-specific lipases, respectively.

The acetone-ether powders had an activity level of 0.3 units/mg solid. One unit will hydrolyze 1.0 nanoequivalent of fatty acid from a triacylglycerol in $1 \mathrm{~h}$ under the above conditions. Figure 1 shows the TLC chromatogram of the hydrolysates obtained from olive oil triacylglycerols by lipase preparations of scallop hepatopancreas, porcine pancreas, and $C$. cylindracea. Unhydrolyzed triacylglycerols $(R f 0.61)$, free fatty acids ( $R f 0.40)$, diacylglycerols $(R f 0.21$ and 0.14 ), and monoacylglycerols $(R f 0.01)$ were clearly resolved on borate TLC using $n$-hexane-ether $(60: 40, \mathrm{v} / \mathrm{v})$ as the developing solvent. As expected, $C$. cylindracea lipase showed two clearly resolved diacylglycerol spots, which represent $s n-1,3$ - and $s n-1,2(2,3)$-isomers; porcine pancreatic lipase showed only the $s n-1,2(2,3)$-isomer spot. The scallop lipase preparation also showed only one diacylglycerol spot, which had the same $R f$ value as that of the $s n-1,2(2,3)$ diacylglycerols obtained from the triacylglycerols by porcine pancreatic and $C$. cylindracea lipases. These results clearly show that the lipase preparation from scallop hepatopancreas is highly specific for the $s n$-1(3)-position of long-chain triacylglycerol molecules. Patton and Quinn ${ }^{6)}$ reported that the digestive lipase of the surf clam Spisula solidissima was capable of hydrolyzing the oleate or palmitate in the $s n$-1(3)-position of triacylglycerol molecules. Except for their study, there are no reports on the positional specificity of bivalve lipase, although 1,3-specific lipase has been found in fish. ") The hepatopancreas of scallops is inedible and is an untouched marine resource. The present study suggests that the hepatopancreas would be a potential source of 1,3-specific lipases.

\section{References}

1) K. Hayashi and M. Yamada: Bull. Fac. Fish. Hokkaido Univ., 26, 182-191 (1975)

2) T. Takagi, K. Hayashi, and Y. Itabashi: Nippon Suisan Gakkaishi, 50, 1413-1418 (1984)

3) M. Bier: in "Methods in Enzymology" (ed. by S. P. Colowick and N. O. Kaplan), Vol. 10, Academic Press, New York, 1955, pp. $627-642$.

4) F. E. Luddy, R. A. Barford, S. F. Herb, P. Magidman, and R. W Riemenschneider: J. Am. Oil Chem. Soc., 41, 693-696 (1964).

5) A. E. Thomas, III; J. E. Scharoun, and H, Ralston: J. Am. Oil. Chem. Soc., 42, 789-792 (1965).

6) J. S. Patton and J. G. Quinn: Mar. Biol, 21, 59-69 (1973)

7) M. K. Munkundan, K. Gopakuman, and M. R. Nair: J. Sci. Food Agric., 36, 191-203 (1985). 